\title{
УНИВЕРСАЛЬНОЕ, НАЦИОНАЛЬНО-СПЕЦИФИЧЕСКОЕ И УНИКАЛЬНО-ЛИЧНОСТНОЕ В РУССКОЯЗЫЧНЫХ ПЕРЕВОДАХ СТИХОВ ТУРКМЕНСКОГО ПОЭТА МАХТУМКУЛИ ФРАГИ'
}

\section{UNIVERSAL, NATIONALLY SPECIFIC AND UNIQUELY PERSONAL IN RUSSIAN TRANSLATIONS OF POEMS BY THE TURKMEN POET MAKHTUMKULI FRAGI \\ L. Muhammad M. Alymov}

Summary: The article is devoted to the poems of the Turkmen poet Makhtumkuli fragi in the aspect of intercultural communication.

The relevance of the research lies in the reading and study of the poetic population of Makhtumkuli fragi, presented in the translations of Russian poets, which is interpreted as intercultural communication of representatives of the Turkmen and Russian ethnocultures.

The purpose of the work is to identify the universal and differential components of a literary text, assessed from the standpoint of intercultural communication: communication between representatives of Russia and Turkmenistan.

The novelty of the work lies in the identification of the universal, nationally specific and uniquely personal in the verses of the Turkmen poet translated into Russian.

Keywords: intercultural communication, Turkmen poet, Makhtumkuli frags, poems and translations, universal and differential.
Мухаммад Людмила Петровна

д.n.н., профессор, Московский государственный лингвистический университет; Российский университет

дружбы народов

ludmilamuh@yandex.ru

Алымов Мухаммед Атамурадович

Московский государственный лингвистический университет

Аннотация: Статья посвящена стихам туркменского поэта Махтумкули фраги в аспекте межкультурной коммуникации.

Актуальность исследования состоит в чтении и изучении поэтического наследия Махтумкули фраги, представленного в переводах русских поэтов, что интерпретируется как межкультурная коммуникация представителей туркменской и русской этнокультур.

Цель работы заключается в выявлении универсального и дифференциального компонентов художественного текста, оцениваемого с позиции межкультурной коммуникации: коммуникации между представителями России и Туркменистана.

Новизна работы состоит в выявлении универсального, национально специфического и уникально-личностного в переведённых на русский язык стихах туркменского поэта.

Ключевые слова: межкультурная коммуникация, туркменский поэт, Махтумкули фраги, стихи и переводы, универсальное и дифференциальное.

формирования культуры отношений и общения, что предполагает глубокое проникновение в культуру других стран, приобщение к ценностям других людей, иными словами то, что составляет основу межкультурной коммуникации (далее: МKK).

В современной жизни МКК является наиболее уязвимой сферой отношений в мультикультурном обществе, поскольку предполагает процесс коммуникативного взаимодействия между представителями разных национальностей и этнокультур.

Актуальность исследования состоит в чтении и изучении художественного текста контактирующих народов, в познании культуры этих народов, их традиций и самобытности.

Цель работы - выявление особенностей художе-

Формирование нового общества невозможно без

Статья подготовлена в рамках поддержанного РФФИ научного проекта № 19 - 013 - 00627 
ственного текста в МКК представителей России и Туркменистана на материале русскоязычных переводов поэтических произведений уникального туркменского поэта Махтумкули фраги.

Предмет исследования - стихи туркменского поэта Махтумкули фраги в аспекте МКК.

Методологическую основу исследования в процессуальном плане определяет межкультурный подход, иные же его компоненты интегрированы на базе этого подхода. Так, применяя данный подход возможно выявить как универсальные, так и дифференциальные информативные единицы, представляющие две (или более) культуры/этнокультуры. Согласно избранному подходу, исследователь и интегрирует, и дифференцирует, и концептуализирует разноуровневые компоненты целостного произведения [1; 3; 4; 15]. Однако ядро данного подхода составляют три базовых принципа антропологической науки (лингводидактики): атропологический, коммуникативный и когнитивный; причём центральную часть фрейма первого (базового) принципа составляет концепт человека, личности выработанный антропологической философией $[1 ; 10]$. Разумеется, этический компонент включён в выстраиваемую модель как её конституирующее ядро [3; 4; 7].

В качестве теоретических работ к исследованию привлекались работы таких ученых, как Д. Бхавук, Г. Триандис, Н.А. Мартыновой, А.П. Садохина, И. Сафоновой, Е.Ф. Тарасова, Тер-Минасовой и других $[3 ; 4 ; 5 ; 9 ; 11 ; 12$; $13 ; 14]$.

Опираясь на вышеперечисленные работы, представим базовое определение: понятие межкультурной коммуникации мы можем определить на основе понятий общение/коммуникация. Так, Е. Ф. Тарасов и Н. А. Мартынова склоняются к тому, чтобы воспринимать данные термины как синонимы $[11 ; 5$, с. 148].

В данной работе, опираясь на мнение выше, а также на мнения других учёных [8] мы всё же дифференцируем понятия межкультурное общение и межкультурная коммуникация. Мы, вслед за Л.П. Мухаммад, Обид Хайдером, Линь Сяоюе, считаем, что понятие межкультурное общение предполагает ситуацию, когда имеет место обратная связь [8], в то время, как понятие межкультурная коммуникация может отражать, в том числе, и ситуацию, когда обратная связь по тем, или иным причинам отсутствует. В любом случае понятие межкультурная коммуникачия шире, оно может и включать, и не включать в свой состав феномен межкультурное непосредственное, контактное по своей природе, общение [8].

С точки зрения поставленной нами цели нам также необходимо рассмотреть понятие межкультурная компетенция. Понятие межкультурная компетенция пред- ставлено в работе А.П. Садохина, который полагает, что межкультурной компетенцией, в идеале, должен владеть человек, вступающий в межкультурную коммуникацию и предполагающий завершить её благополучно [9]. Вслед за А.П. Садохиным мы считаем, что явление межкультурной компетенции имеет иерархическую структуру и охватывает социокультурные знания и способности, прежде всего умение соотносить и анализировать элементы культуры, языка, коммуникативных стратегий, и опыт владения языком, используемым для межкультурного общения [9]. В дополнение к сказанному добавим, что в соответствии с концепцией культурных стандартов межкультурная компетенция понимается как «способность и готовность интегрировать иностранные культурные стандарты в свою собственную модель восприятия, мышления, оценки и действий» [9].

В контексте всего сказанного мы думаем, что акт обращения, например, русского поэта к художественному наследию поэта иной культуры и, как результат, создание успешного перевода охватывает как феномен МКК, так и феномен межкультурной компетенции, ибо именно успешный перевод является неопровержимым доказательством способности поэта-переводчика завершить акт результативно. Более подробно рассмотрим сказанное на примере переводов поэзии уникального туркменского поэта Махтумкули фраги русскими поэтами-переводчиками, прежде всего Ю. Гордиенко, Г. Шенгели, А. Тарковским.

Как известно, феномен человеческого опыта возможно четко определить в чётко очерченных сочиальных пространствах, которые как с точки зрения различных этнокультур, так и с точки зрения эпох различны [15]. Таким образом, события и явления, оригинальные авторские идеи и самого автора, объекта и субъекта определённого континуума, следует интерпретировать в одной связке с этим континуумом: временным, а также пространственным.

У каждой нации есть свои величайшие поэты. В Туркмении таким поэтом по праву считается Махтумкули фраги.

Общеизвестно, что ещё с древних времён поэты осмысливали себя и своё место в мире, в народной памяти. В этом плане в культурном пространстве России мы обнаруживаем стихи М.В. Ломоносова, В.А. Жуковского, А.С. Пушкина. С детства всем русским людям известны строчки: «Я памятник себе воздвиг нерукотворный». Созвучны русским стихам и стихи туркменского поэта Махтумкули фраги:

Куда бы дороги туркмен не вели, Расступятся горные кряжи земли. Потомкам запомнится Махтумкули, Поистине станет устами Туркмении. 
Махтумкули фраги родился в 1733 году в Хаджи Говшане, к востоку от Кумбажовуза Атракского района, в селе Гызылбаир (ныне Шарлавук) в семье классика туркменской литературы Довлетмаммада Азади (17001760).

С раннего возраста он читал книги на арабском и персидском языках и был обязан этому богатой библиотеке отца.

После окончания учебы в Медресе Идрис-Баба в Гызыл-Аяге Бухарского ханства, а также в знаменитом Медресе Кекилдаш в Бухаре он через Узбекистан, Таджикистан и Афганистан отправился в северную Индию, и в Хиву, один из научных центров того времени с множеством Медресе.

Личная жизнь Махтумкули была полна трагедий. В 1754 году трое членов его семьи - его сестра Ханманлы, его младший брат Джанасан и его жена Байрам умерли в один день, что оставило 21-летнего Махтумкули, его отца Азада и его мать в глубоком горе.

Несчастия Махдумгулу (Махтумкули) продолжались и в будущем: выходит замуж за другого девушка, которую он страстно любил: «Я крепость строил - рухнула стена. В свою же мне попасться сеть пришлось. Махтумкули, по воле волн, плыви, Нет берегов, страдалеи, улюбви...».

Время идёт, а Судьба продолжает испытывать теряющего силы поэта на прочность: умирают два его старших брата... , в молодом возрасте умирают оба его ребенка:

Кёроглу, рвение единственное оставил,

Я стар, я потерял силы,

Я потерял двоих детей - свое детище,

Пощады не было, удача моя черная (из стихотворения «Моя удача черная»).

Удача «чёрная» отражена и в стихах Махтумкули, написанных на смерть отца: «Где имам? Я стою, как пустая мечеть. Где луна? Небесам не дано просветлеть».

В 1760 году Махтумкули путешествует по Мангышлаку, Астрахани, Азербайджану, а оттуда отправляется на Ближний Восток. Путешествия и их изображение в стихах является поэтической традицией Востока. Не случайно в своих стихах Махтумкули часто отсылает читателя к столпам персидской поэзии - Хайяму, Хафизу, Низами и Фирдоуси. Таким образом, известность Махтумкули в Средней Азии объяснима не только географическим фактором, но и самой поэтической традицией, в рамках которой он работал: стихотворения Махтумкули (в соответствии с поэтической традицией) отразили тот мир, который предстал в глазах поэта во время его путешествий: в стихах упомянуто много стран, провинций, го- родов, сел. Например, говоря об Иосифе, поэт не мог не упомянуть Ханаан (ныне Палестину) и Египет.

В стихотворной традиции того времени поэт представляет как посещённые им страны, так и далёкие, существующие в его поэтическом воображении:

«Двенадцать тысяч деревьев чайной Индии,

Шесть тысяч деревьев дорога-Румистан,

Четыре тысячи Саклаб, Санджаб, четыре тысячи Зангистан,

Как будто этот мир - потоп.

Четыре тысячи ярдов от Йемена, тысяча от Болгарии,

Земля может быть как греческой, так и одинарной хазарской,

Тысяча деревьев - дорога горная, великан,

Тогда этот мир уйдет ...

Три тысячи триста деревьев - это люди ислама,

Ирак, Азербайджан, Египет, Дамаск,

Полно в Хорасане, Персии, Безиркухе,

Когда он исчезает, этот мир превращается в скандал» (из стихотворения поэта «Этот мир»).

В свете исламских традиций территория 15 стран оформлена деревьями, водой, болотами, горами, безлюдными местами, пустынями и т.д.

Стихи Махтумкули о путешествиях и о дальних, ещё не посещённых, странах как будто заживляют почти иссохшую в страданиях душу поэта, благодаря творческому воображению и стихам он впитывает в себя живую исцеляющую влагу. Вместе с тем рождаются те абсолютно новые смыслы, которые, по мнению русского писателя Н.В. Гоголя, могут родиться только в душе, пережившей неимоверные страдания. Так, в таких стихах, как «Аджаб айям гельмеди», «Мохтадж эйлема», «Агларам», «Гозлер», «Донду», «Килди», «Бичарайам» появляются на свет такие феномены, как мужество-богатство, бедность-богатство, ложная правда, вор-правда.

В Европе первые сведения о Махтумкули Фраги стали появляться в середине XIX века. В Лондоне польским литератором и ученым Л. Ходзько-Борейко была опубликована на английском языке краткая биографическая справка о Махтумкули и три его стихотворения.

На русском языке стихи Махтумкули появились в 1872 году в переводах Ф. Бакулина: посредством подстрочного перевода были представлены первые два стихотворения.

Однако пика славы творчество Махтумкули фраги достигло в XX веке в условиях СССР. Наряду с учеными, академиками и профессорами Н. А. Остроумовым, А.Н. Самойлович, Е.Э. Бертельс Б. Каррыевым, М. Косаевым, 3. Мухаммедовой большой вклад в изучение творчества 
Махтумкули внесли такие замечательные российские литераторы и переводчики, как Ю. Гордиенко, Г. Шенгели и А. Тарковский. Последний как блистательный мастер именно стихотворного перевода сыграл особую роль в распространении творчества Махтумкули фраги:

\section{Добро и зло}

«Народу - сила, мир, беседа,

Семейных очагов тепло;

Джигиту - битва и победа,

Булат и крепкое седло.

Ложь предоставь на все готовой

Мирской молве. Не надо слова

Ни раздраженного, ни злого:

Народ мой ненавидит зло....»

Общеизвестно, что у хорошего переводчика поэт как бы заново рождается в другом языке. Так случилось и с жизнью стихов Махтумкули фраги в пространстве русской культуры и русского слова. С точки зрения универсального, дифференциального и уникально-личностного это стихотворение можно разделить на три части:

1. Несомненно, что разделение всего, что происходит в мире на добро и зло - главная и универсальная часть поэтического произведения. К универсальной части отнесём и начальные строчки «Народу - сила, мир, беседа, Семейных очагов тепло».

2. В строчках «Джигиту - битва и победа, Булат и крепкое седло» мы определяем как универсальную, так и национально специфическую части: 1) к универсальной части отнесём: а) мужественного человека, потенциального бойца, субъекта действий по защите Родины (в стихе он обозначен номинацией «джигит»); б) победу как предпочтительный результат в битве, на войне; в) средство, инструмент, при помощи которого побеждают («булат и ... седло»); г) качество инструмента (крепкое седло); 2) к национально специфической части (причём являющейся универсальной для целых регионов) можно отнести явления, обозначенные безэквивалентными лексическими единицами (ЛЕ): а) «джигит» (субъект действия); б) «битва и победа» (исторически обусловленное, силой традиции предписанное джигиту «предназначение»); в) «Булат и крепкое седло» (средства, инструмен- ты, без которых и понятие «джигит» в его первичном значении - пусто); г) «крепкое седло» - словосочетание (метонимия), под которым понимается целый комплекс снаряжений (средств, инструментов) джигита: боевой конь вместе с его снаряжением: крепким седлом, булатом и т.д.

3. Третья часть «Ложь предоставь на все готовой Мирской молве. Не надо слова Ни раздраженного, ни злого» - отражение субъективного мира поэта, его восприятия «на все готовой Мирской молвы», где ей спокойно, без суеты, в силу традиции отводится удел лжи (причём, по контексту, лжи злой). И вдруг ... неожиданный поворот: переосмыслив стереотипную номинацию «злое слово» как в принципе зло, поэт поднимается выше стереотипов традиционного сознания и заключает: «народ мой ненавидит зло».

В поэзии Махтумкули фраги мотивы отчуждения, одиночества, ссылки, разлуки и лишений весьма часто одариваются неожиданным счастьем наслаждения красотой мира, чаще всего мира природы. Однако случается и наоборот: величественный дворец из базилика, вершин и тумана, каким ощущает себя поэт, в миг превращается в руины, свидетельствующие о великой человеческой трагедии:

«Я был базиликом в Ираме,

Я был зеброй на родине,

я был стар и храбр,

Я был в тумане на вершине горы,

Разница в том, что я был в безопасности,

Теперь я разрушенный дворец» (из стихотворения «Я беден»).

Великий русский поэт А. Блок писал: главной отличительной чертой настоящего поэта является пройденный им путь. Стихи Махтумкули фраги являются несомненными свидетелями пройденного поэтом пути: от национально специфического - к универсальному, а затем уже к личному, субъективному и уникальному. В качестве примера такого личного, уникального, можно назвать и представленное выше стихотворение «Я беден», где (казалось бы) занимающее очень маленькое пространство поэтическое произведение засверкало сокровищами его богатой и цельной души.

1. Ашчи М., Мухаммад Л.П., Татаринова Н.В. Межкультурная коммуникация как компонент антропологической лингводидактики. Вестник Российского университета дружбы народов. Серия: Русский и иностранные языки и методика их преподавания. 2018. Т. 16. № 2. С. 143-156.

2. Бхавук Д., Триандис Г., Роль теории культуры в изучении культуры и межкультурного обучения//ред. В.Д. Лэндис и Р.В. Брислин. Справочник по межкультурному обучению. Thousand Oaks: Sage. 1996. С. 17-34.

3. Казмир Фред. Строительство третьей культуры: смена парадигмы международного и межкультурного общения. Ежегодник коммуникаций, № $16,1993$. $428 \mathrm{c}$. 
4. Казмир Фред. Основы изучения межкультурной коммуникации на основе модели построения третьей культуры. Международный журнал межкультурных отношений, № 23(1), 1999. С. 91-116.

5. Мартынова Н.А. Межкультурная коммуникация как особый вид общения. Омский научный вестник. № 2 (54). 2007. С. 148-151.

6. Махтумкули (Фраги). Избранное. Перевод А. Тарковского, М. Тарловского, Г. Шенгели и др. , 1974. 342 с.

7. Мухаммад Л.П., Мухаммад Х.И.А., Хетагурова Н.Н. Антропологический аспект разработки понятия субъективности в советском и постсоветском пространстве. В сборнике: Мир русского слова и русское слово в мире. Материалы ХІ Конгресса Международной ассоциации преподавателей русского языка и литературы. 2007. С. 222-226.

8. Мухаммад Л.П., Обид Х.О., Линь С. О понятии «общение как деятельность» применительно к обучению иностранцев в соответствии с антропологическим принципом гуманитарных наук. Современная наука: актуальные проблемы теории и практики. Серия: Гуманитарные науки. 2021. № 3. С. 104-109.

9. Садохин А.П.П. Межкультурная компетентность. Журнал социологии и социальной антропологии. 2007. Том Х. № 1. Электронный ресурс. Режим доступа: https://cyberleninka.ru/article/n/mezhkulturnaya-kompetentnost-ponyatie-struktura-puti-formirovaniya.

10. Слободчиков В.И., Исаев Е.И. Основы психологической антропологии. Психология человека: Введение в психологию субъективности. Учебное пособие для вузов. М.: Школа-Пресс, 1995. 384 с.

11. Тарасов Е.Ф. Межкультурное общение - новая онтология анализа языкового сознания// Этнокультурная специфика языкового сознания. М.: Институт языкознания РАН, 1996. С. 7 - 22.

12. Busch, Dominic (2009). The notion of culture in linguistic research . Forum Qualitative Sozialforschung / Forum: Qualitative Social Research, 10(1), Art. 50, [Электронный ресурс], режим доступа: http://nbn-resolving.de/urn:nbn:de:0114-fqs0901508 (Дата обращения 20.12.2020 г.).

13. Erickson F. Métodos cualitativos de investigación sobre la enseñanza. In Merlin Wittrock (Ed.), La investigación de la enseñanza, II. Métodos cualitativos y de observación. Barcelona: Paidós/M.E.C.1989-195-301 p.

14. Casmir F. Third-culture building: A paradigm shift for international and intercultural communication. Communication Yearbook, 16, 1993. P. $407-428$.

15. Chubarova 0.E., Stoletova E.K., Starodubova 0.Yu., Muhammad L.P. Polylogue of cultures and epochs in the course of reading a literary text in a foreign audience Revista Gênero e Direito. 2020. T. 9. № 1S1. C. 505-522.

○ Мухаммад Людмила Петровна (ludmilamuh@yandex.ru), Алымов Мухаммед Атамурадович.

Журнал «Современная наука: актуальные проблемы теории и практики»

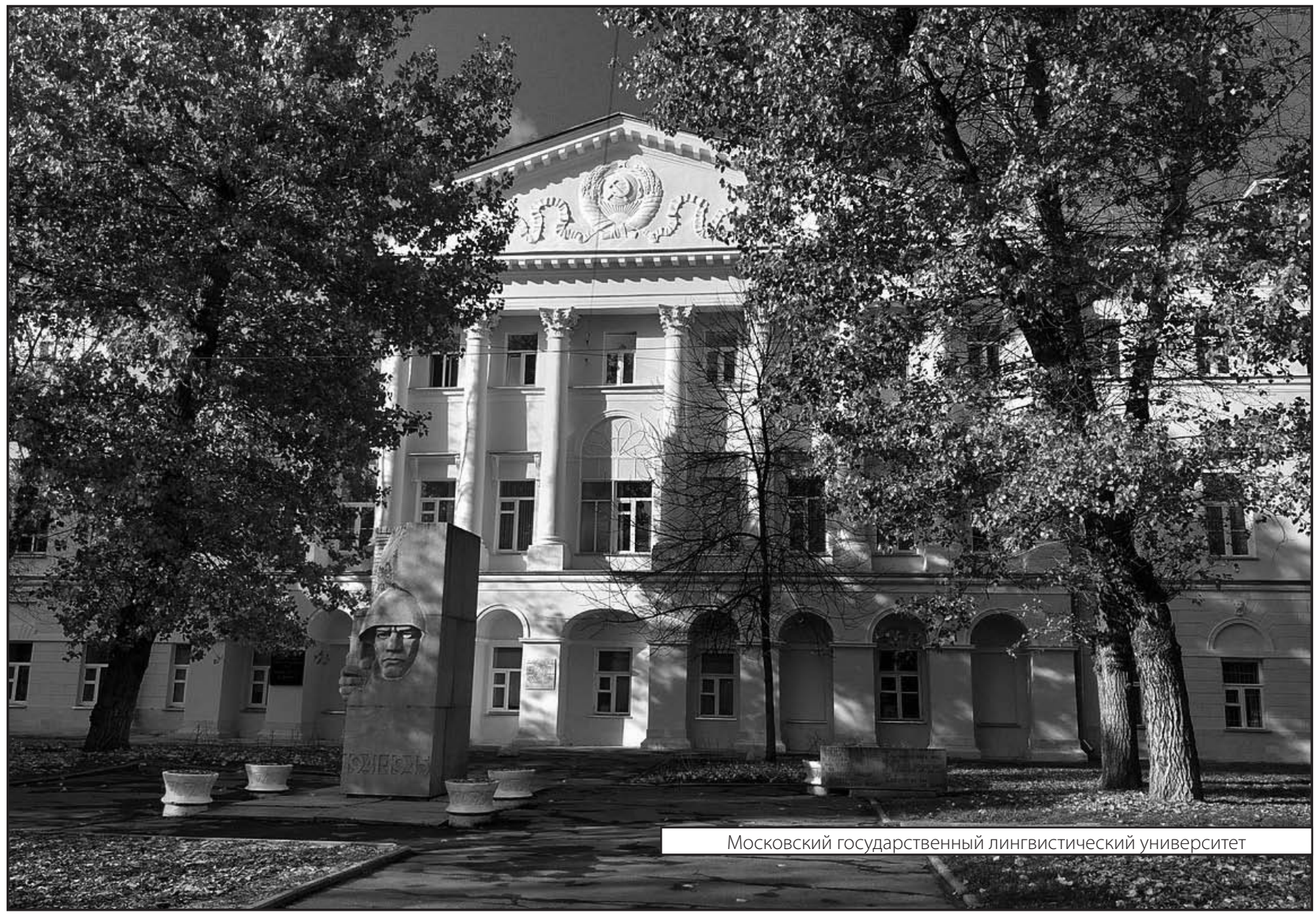

